\title{
Trajetórias profissionais na constituição das Ciências Sociais e Humanas em Saúde na Abrasco
}

I ${ }^{1}$ Aurea Maria Zöllner lanni, ${ }^{2}$ Cristiane Spadacio, ${ }^{3}$ Renato Barboza, ${ }^{4}$ Olga Sofia Fabergé Alves, ${ }^{5}$ Sabrina Daniela Lopes Viana, ${ }^{6}$ Ane Talita Rocha I

Abstract: Nos dias de hoje, é cada vez mais perceptível a importância das Ciências Sociais para a consolidação da Saúde Coletiva no Brasil. Compreender, portanto, a trajetória dos profissionais que de certa forma fundaram o campo e o mantiveram é, enfim, compreender a própria trajetória teórica e prática dessa área, evidenciada, também, nos congressos de Ciências Sociais em Saúde realizados pela Abrasco. No contexto dessa discussão, o presente artigo realiza um mapeamento do perfil dos presidentes da Abrasco e dos coordenadores das Comissões de Ciências Sociais que ocuparam esses cargos entre 1995 e 2011, anos em que aconteceram os Congressos Brasileiros de Ciências Sociais e Humanas em Saúde. Foram realizadas 13 entrevistas com presidentes da Abrasco e com os coordenadores das Comissões de Ciências Sociais, em suas diferentes gestóes. Apesar de este artigo assumir caráter mais descritivo acerca da constituição e institucionalização das Ciências Sociais em Saúde na Abrasco, acredita-se que a compreensão do processo de conformação desse subcampo a partir da fala dos agentes que o constituem seja extremamente profícua para os debates atuais sobre o lugar das Ciências Sociais no campo da Saúde Coletiva.

> Key words: Saúde Coletiva; Ciências Sociais em Saúde; trajetórias profissionais.

\author{
1 Faculdade de Saúde Pública, \\ Universidade de São Paulo. \\ Prática em Saúde Pública. \\ São Paulo-SP, Brasil. Endereço \\ eletrônico: aureanni@usp.br \\ 2 Faculdade de Saúde Pública, \\ Universidade de São Paulo. \\ Prática em Saúde Pública. \\ São Paulo-SP, Brasil. Endereço \\ eletrônico: cris.spadacio@ \\ gmail.com
}

${ }^{3}$ Instituto de Saúde, Secretaria de Estado da Saúde de São Paulo. Núcleo de Práticas em Saúde. São Paulo-SP, Brasil. Endereço eletrônico: renato@ isaude.sp.gov.br

${ }^{4}$ Instituto Butantan, Laboratório de História da Ciência. São Paulo-SP, Brasil. Endereço eletrônico: olgasofia@uol.com.br

${ }^{5}$ Faculdade de Saúde Pública, Universidade de São Paulo. Prática em Saúde Pública. São Paulo-SP, Brasil. Endereço eletrônico: sabrinadlv@yahoo. com.br

${ }^{6}$ Faculdade de Filosofia, Letras e Ciências Humanas, Universidade de São Paulo. São Paulo-SP, Brasil. Endereço eletrônico: ane. rocha@usp.br
Recebido em: 16/10/2013 Aprovado em: 28/09/2014 
As Ciências Sociais e suas disciplinas constitutivas oferecem um rico arsenal teórico, conceitual e metodológico para a saúde (GABE; CALNAN, 2009; BROOM; WILLIS, 2007). No Brasil, essa contribuição foi fundamental para o campo da Saúde Coletiva (NUNES, 1999; SARTI, 2010), que se constitui em meados da década de 1970 na interface da produção de conhecimentos e de práticas. Multifacetado, esse campo configura-se originalmente por três grandes conformações disciplinares: a Epidemiologia; a Política, Planejamento e Gestão, e as Ciências Sociais. Atualmente, acrescenta-se uma formação em Ciência e Tecnologia em Saúde, todas elas convivendo com demais iniciativas, como a de saúde e ambiente e vigilância sanitária, por exemplo.

Tomaremos aqui como base a noção de campo de Pierre Bourdieu, que, segundo Nunes, "é uma esfera da vida social que foi se automatizando progressivamente através da história em torno de um certo tipo de relações sociais, de interesses e de recursos próprios" (NUNES, 2005, p. 16). Para Bourdieu, o campo é um universo intermediário entre o que ele chama de conteúdo textual de determinada produção científica ou cultural e seu contexto social, e é nesse universo intermediário que se inserem "[...] os agentes e as instituições que produzem, reproduzem ou difundem a arte, a literatura ou a ciência. Esse universo é um mundo social como os outros, mas que obedece a leis sociais mais ou menos específicas" (BOURDIEU, 2004, p. 20). Nesse sentido, a noção de campo designa um espaço relativamente autônomo, um microcosmo dotado de leis próprias, não independente das dinâmicas e processos sociais gerais.

Originalmente, o campo da Saúde Coletiva no Brasil delineou-se a partir do movimento da Medicina Social, desencadeado na América Latina nas décadas de 1950 e 1960, quando se incentivou a formalização e a incorporação dos conteúdos de ciências sociais nos cursos de Medicina em função da implementação do projeto preventivista (NUNES, 2009). Entretanto, como campo, só se estruturará formalmente a partir dos anos 1970, “[...] especialmente [focado] na formação de recursos humanos, no avanço das Ciências Sociais na saúde e no papel da Financiadora de Estudos e Projetos (Finep) no fomento ao desenvolvimento tecnológico e inovação" (NUNES, 2009, p. 23).

Com base nas origens médico-sociais, a Saúde Coletiva configura-se como uma invenção eminentemente brasileira, diferenciando-se da construção 
conceitual que estruturava a Saúde Pública até então (LOYOLA, 2012; PAIM; ALMEIDA FILHO, 1998). As Ciências Sociais foram incorporadas de forma ativa e sob intensos debates de natureza teórica e prática, principalmente ancoradas nos marcos do materialismo histórico-dialético (CANESQUI, 1995; ESCOREL, 1999; NUNES, 1985; 1999; TEIXEIRA, 1985), e, de acordo com Loyola (2012), a presença das Ciências Sociais na Saúde Coletiva é estrutural, alicerçando esse campo, essa área de conhecimento.

Atualmente, é possível compreender as Ciências Sociais em Saúde como um subcampo da Saúde Coletiva, produto da interface de dois outros campos de conhecimento - o das Ciências da Saúde e o das Ciências Sociais (BARROS; SPADACIO, 2011). A ênfase aqui se deve ao fato de que estas, na origem da Saúde Coletiva, foram protagonistas da mediação de significados teóricos e metodológicos junto à Epidemiologia e às práticas biomédicas, num esforço interdisciplinar que envolveu a problematização conceitual do objeto saúde e resultou na formulação do conceito de determinação social do processo saúdedoença (IANNI, 2011a; 2011b; PAIM, 2007). A incorporação do termo humanas ao subcampo das Ciências Sociais em Saúde ocorreu posteriormente, abrindo seu leque institucional e acolhendo, finalmente e de forma explícita, disciplinas como a Filosofia, uma importante protagonista do debate da Saúde Coletiva desde o seu início, e a Psicologia, dentre outras. Atualmente o subcampo é denominado de Ciências Sociais e Humanas em Saúde (CSHS).

Nessa perspectiva, pode-se dizer que é juntamente com a instituição da Associação Brasileira de Pós-Graduação em Saúde Coletiva (Abrasco) em 1979, e suas comissões internas, que se dá a institucionalização do campo da Saúde Coletiva e, nele, o subcampo das CSHS (IANNI et al., 2012). O esforço dessas diferentes articulações no contexto do movimento da Reforma Sanitária, pôs em discussão práticas e saberes em saúde então instituídos, tendo, de acordo com Paim (2009), problematizado três aspectos principais: a saúde como área de saber; a saúde como setor produtivo e a saúde como situação de vida.

Naquele contexto, as Ciências Sociais em Saúde assumiram, ainda, uma particularidade: a capacidade de elaboração crítica ao modelo biologizante (NASCIMENTO, 2011). Por tudo isso, é possível falar em um pensamento social em saúde, produto correlato à configuração de um campo científico e político (IANNI et al., 2012). 
Tal pensamento, com suas formulações teóricas, conceituais e metodológicas, não se concebeu de forma circunscrita e delimitada ao cenário tradicional e próprio das Ciências Sociais brasileiras, ou seja, dentro dos departamentos de Sociologia, Antropologia, Ciência Política, ou outros, das escolas de Ciências Sociais do Brasil. Desenvolveu-se institucionalmente e de forma interdisciplinar pelos atores envolvidos na saúde, alunos e docentes de graduações dessa área ou das pós-graduações em Saúde Coletiva/Saúde Pública, profissionais e intelectuais dos serviços de saúde e outros, ou seja, sujeitos sociais que historicamente vinham se encarregando da produção e difusão desse conhecimento das Ciências Sociais na área da saúde.

\section{As Ciências Sociais e Humanas na Abrasco}

Como um braço constitutivo da Saúde Coletiva, as Ciências Sociais em Saúde instituíram-se em 1986, sendo consolidadas em 1994 pela Comissão de Ciências Sociais e Humanas em Saúde da Abrasco. Essa consolidação envolveu, também, a realização dos Congressos Brasileiros de Ciências Sociais em Saúde, posteriormente denominados de Congressos Brasileiros de Ciências Sociais e Humanas em Saúde da Abrasco.

O diálogo interdisciplinar tem sido, talvez, um dos aspectos mais relevantes desse subcampo (NUNES, 2005; CANESQUI, 2008) e, evidentemente, essa "dança” entre as diversas disciplinas constitutivas da Saúde Coletiva não acontece de forma harmônica ou bem estruturada em todos os momentos.

Retomando Bourdieu (2004), a Saúde Coletiva é um campo historicamente construído, com poderes institucionalizados próprios e lógicas de ação guiadas pelos agentes que o constituem. Nesse sentido, os conflitos e disputas entre os agentes estruturam esse campo científico, cujos subcampos como as CSHS, por exemplo, são postos em tensão, gerando disputas por recursos e posições internas ao campo. Tais conflitos envolvem uma dupla dimensão: política e epistemológica.

Nas CSHS, uma das tensões emblemáticas se refere à incorporação dos conceitos das Ciências Sociais na saúde, muitas vezes realizada de forma simplista e superficial, metodológica e teoricamente. É possível notar esse afrouxamento metodológico, por exemplo, quando predomina a lógica quantitativista da produção de conhecimento (LOYOLA, 2012). Nessa "dança", entretanto, a 
Saúde Coletiva não escapa às Ciências Sociais e Humanas, na medida em que se encontra envolvida e nutrida pelas disciplinas dessa área.

Compreender, portanto, a trajetória dos profissionais que fundaram o campo da Saúde Coletiva e o mantiveram ativo até hoje é, de certa forma, compreender a trajetória teórica e prática do subcampo das CSHS, também evidenciada nos Congressos de Ciências Sociais em Saúde realizados pela Abrasco. Não se pode desconsiderar, contudo, a produção de cientistas sociais, realizada de maneira esparsa e isolada nas escolas tradicionais de Ciências Sociais e Humanas, que poderiam constituir, eventualmente, outro objeto de reflexão e estudo acerca do diálogo das Ciências Sociais e a saúde.

Partindo do pressuposto bourdieuano de que o universo dos agentes e instituições é fundamental à compreensão de um campo científico, o estudo das trajetórias dos profissionais da Saúde Coletiva e das CSHS contribui para a compreensão do campo e de seu subcampo.

O presente artigo realiza um estudo do perfil dos presidentes da Abrasco e dos coordenadores das comissóes de CSHS que ocuparam esses cargos entre 1995 e 2011, período de realização dos cinco primeiros Congressos Brasileiros de Ciências Sociais e Humanas em Saúde.

\section{Metodologia}

As CSHS configuram-se como subcampo no interior da Saúde Coletiva. Pressupondo que a história de um campo é simultaneamente a história dos seus atores (BOURDIEU, 2004), a realização de entrevistas com seus agentes é extremamente elucidativa do processo de sua constituição.

O material que subsidia este trabalho provém de entrevistas realizadas pela pesquisa "Questões contemporâneas nas Ciências Sociais em Saúde: o estudo de temas emergentes nos congressos brasileiros de Ciências Sociais e Humanas em Saúde, Abrasco 1995-2007” (IANNI et. al. 2012). São 13 entrevistas semiestruturadas com presidentes da Abrasco $(n=05)$ e coordenadores das comissões de CSHS ( $\mathrm{n}=08$ ) das diferentes gestôes da associação entre 1995 e 2007, período de realização dos cinco primeiros Congressos Brasileiros de Ciências Sociais e Humanas em Saúde.

A realização das entrevistas decorreu da compreensão de que esses agentes, ao ocuparem cargos institucionalmente estabelecidos na Abrasco, expressariam, para 
além de suas experiências particulares, a trajetória institucional do subcampo. Sendo assim, as entrevistas foram estruturadas com o objetivo de identificar o perfil desses agentes, suas formações disciplinares e trajetórias profissionais na saúde, além de investigar, a partir da sua ótica particular, posicionamentos críticoanalíticos sobre a relevância e a evolução dos Congressos de Ciências Sociais e Humanas em Saúde e sobre os temas emergentes no cenário dos Congressos Brasileiros do subcampo e na Saúde Coletiva em geral.

O roteiro de entrevistas foi único e aplicado aos dois perfis de informantes, tendo sido estruturado em três eixos temáticos: 1) identificação dos entrevistados: dados pessoais, formação básica e pós-graduada e trajetória pessoal nas CSHS; 2) as Ciências Sociais na ABRASCO, envolvendo desde questôes gerais, como o contexto de constituição do subcampo e inserção na Saúde Coletiva, até questôes relativas aos temas emergentes nesse subcampo e áreas conexas; 3) os Congressos Brasileiros de Ciências Sociais e Humanas em Saúde da Abrasco, mais especificamente questões relativas aos esforços de organização do $1^{\circ}$ Congresso, os debates na definição dos temas, a regionalização dos trabalhos e os desafios e perspectivas para eventos futuros.

As questôes formuladas para cada um desses eixos foram abertas, na perspectiva de captar o relato das experiências cotidianas vivenciadas pelos entrevistados. Sabe-se que a estratégia de realizar entrevistas permite ao informante grande autonomia de expressão, evidentemente dentro dos limites temáticos estabelecidos pela pesquisa.

O roteiro de entrevistas passou por pré-testes, para assegurar a qualidade da coleta das informaçóes. Todas as entrevistas foram gravadas, transcritas e submetidas à técnica de análise de conteúdo, compreendendo as fases de exploração do material, pré-análise, análise e sistematização dos resultados (BARDIN, 1979). O projeto foi aprovado pelo Comitê de Ética em Pesquisa do Instituto de Saúde da Secretaria de Estado da Saúde de São Paulo (Protocolo nº. 013/2010).

\section{Resultados}

Os resultados aqui apresentados correspondem, especificamente, ao primeiro dos eixos temáticos do roteiro de entrevistas: a identificação dos informantes, suas formações disciplinares em nível de graduação e pós-graduação e sua trajetória pessoal nas CSHS e na Abrasco. Esses resultados serão apresentados em dois 
blocos distintos: o primeiro correspondendo à análise do perfil dos entrevistados quanto aos dados pessoais e à formação em graduação e pós-graduação; o segundo correspondendo aos relatos das trajetórias pessoais nas CSHS e na Abrasco.

Foram identificados 13 informantes-chave, considerados o período histórico delimitado pela pesquisa e o critério teórico-metodológico - de base bourdieuana - adotado. Cinco dos entrevistados foram presidentes da Abrasco e oito coordenadores da Comissão de Ciências Sociais e Humanas em Saúde. Esse pequeno universo de atores não é homogêneo, cada um apresentando características próprias e diferenciadas.

O quadro abaixo identifica o perfil de formação, a instituição de origem, os cargos exercidos na Abrasco e o período de atuação dos entrevistados:

Quadro I. Perfil institucional dos entrevistados

\begin{tabular}{lllll}
\hline Nome & Formação & Instituição & Cargo & $\begin{array}{l}\text { Período de } \\
\text { atuação }\end{array}$ \\
\hline Ana Maria Canesqui & Serviço Social & FCM/Unicamp & Coordenador & 1994-1997 \\
\hline José Carvalho de Noronha & Medicina & FIOCRUZ & Presidente & $2000-2003$ \\
\hline José da Rocha Carvalheiro & Medicina & DMS/FMUSP/RP & Presidente & 2006-2009 \\
\hline Kenneth Camargo Jr. & Medicina & IMS/UERJ & Coordenador & 2007-2009 \\
\hline Leny Trad & Psicologia & ISC/UFBA & Coordenador & $2009-2013$ \\
\hline Madel T. Luz & Filosofia & IMS/UERJ & Coordenador & 03-07/2003 \\
\hline Maria Cecília de Souza Minayo & Sociologia & ENSP/FIOCRUZ & Presidente & $1994-1996$ \\
\hline Moisés Goldbaum & Medicina & DMP/USP & Presidente & $2003-2006$ \\
\hline Nísia Trindade Lima & Sociologia & COC/FIOCRUZ & Coordenador & 2002-2003 \\
\hline Paulete Goldenbergue & Ciências Sociais & Unifesp & Coordenador & $1999-2000$ \\
\hline Paulo César Alves & Filosofia & ISC/UFBA & Coordenador & $1997-1999$ \\
\hline Rita de Cássia Barradas Barata & Medicina & FCMSCSP & Presidente & $1996-2000$ \\
\hline Silvia Gershman & Ciências Sociais & DASP/ENSP/ & Coordenador & $07 / 2003-2007$ \\
\hline
\end{tabular}

\section{Perfil de formação dos entrevistados}

No que se refere à formação básica, observa-se diferença entre o grupo de presidentes e o grupo dos coordenadores de comissão. Entre os primeiros, predomina a formação graduada em Medicina, destacando-se apenas uma com formação 
em Ciências Sociais, realizada em instituição brasileira e complementada em universidade do exterior, Nova York, Estados Unidos da América do Norte. Os demais desenvolveram suas graduaçôes em universidades brasileiras. No grupo dos coordenadores há maior variedade nas formações básicas; um é formado em Medicina, duas em Ciências Sociais, dois em Filosofia, uma em Sociologia, uma em Psicologia e uma em Serviço Social. À exceção de uma das coordenadoras da Comissão, formada na Universidad de Buenos Aires, Argentina, os demais concluíram suas graduações em universidades brasileiras.

Quanto à formação em nível de pós-graduação, a diversidade é grande nos dois grupos. Quatro dos presidentes da Abrasco têm formação em programas de Medicina Preventiva ou Social, todas elas em instituições brasileiras, à exceção de um dos presidentes, que desenvolveu seu mestrado na Universidad Autónoma Metropolitana de Xochimilo, México, e o doutorado no Brasil. Aúnica presidente da Abrasco com pós-graduação fora da área médica tem mestrado em Antropologia Social e doutorado em Saúde Pública. No que diz respeito à formação pósgraduada dos coordenadores, há grande diversidade, podendo-se identificar três grupos distintos. O primeiro apresenta três entrevistados com formação básica em Medicina, Ciências Sociais e Serviço Social e que desenvolveram suas pósgraduações em Saúde Pública/Coletiva (dois) ou em Medicina Social (apenas uma); a exceção é um mestrado em Ciências Sociais, desenvolvido pela cientista social desse grupo. Todos realizaram suas pós-graduações em instituições brasileiras. Outro grupo, de apenas dois entrevistados, desenvolveu suas pósgraduaçôes em programas interdisciplinares e no exterior: há uma psicóloga doutora em Ciencias Sociales y Salud em Barcelona, Espanha, e um licenciado em Filosofia que realizou seu mestrado em Ciências Sociais e o doutorado em Social and Environmental Studies Sociology, na Inglaterra, Liverpool. O último grupo, de três entrevistados, além da formação básica em Ciências Sociais, completou sua pós-graduação nessa mesma área, mesclando mestrados em Ciência Política e doutorado em Sociologia/Ciências Sociais (dois deles), ou vice-versa (uma delas). Nesse grupo, uma das entrevistadas desenvolveu o mestrado em Louvin, França, na Univesité Catholique e o doutorado em instituição brasileira, como os demais. Observa-se, portanto, que, quanto à formação pós-graduada, o grupo de coordenadores, além de heterogêneo, apresentou maior interface com instituições estrangeiras. 
Sobre a localização em território nacional das instituições formadoras no nível da graduação desses profissionais, observa-se uma concentração na região sudeste do país, especialmente das instituições formadoras dos presidentes da Abrasco, notando-se a ausência de instituições das regiōes Norte e Nordeste, ainda que estas, nos últimos anos, venham-se firmando como importantes polos de ensino e pesquisa no campo. Entre os coordenadores, entretanto, além do espectro de instituições ser mais variado, há também uma maior variação na localização territorial. Apesar de muitas instituições situarem-se no eixo RioSão Paulo, verifica-se que dois coordenadores se formaram na região Nordeste, especificamente na Bahia, e outra, como mencionado, na Argentina. No nível da pós-graduação, a localização territorial das instituições formadoras concentrouse no eixo Rio-São Paulo, apresentando quatro casos de formados fora desse eixo, todos localizados em território estrangeiro: América Latina, especificamente o México, e Europa, especificamente Espanha, França e Inglaterra.

Quanto à época de formação pós-graduada dos entrevistados, verificou-se que ela se estende das décadas de 1960 a 1990, e identificaram-se quatro grupos distintos. No primeiro, um dos presidentes e duas coordenadoras da comissão formaram-se nos anos 1960, década em que iniciaram seus mestrados, tendo realizado, posteriormente, seus doutorados. No segundo grupo, dois presidentes e três coordenadores de comissão iniciaram sua formação pós-graduada na década de 1970, migrando para doutorados desenvolvidos nos anos 1980. No terceiro grupo, três coordenadores de comissão e apenas um presidente iniciaram suas pós-graduações nos anos 1980, tendo uma concluído mestrado e doutorado nessa década e os demais, concluído o doutorado nos anos 1990. No último grupo, uma coordenadora realizou realiza seu doutorado nos anos 1990. Esse longo período indica não só que há várias gerações de formados, como o fato de que a maioria deles, apesar da forte liderança no campo, encontrava-se em processo de formação no bojo do processo de criação da Abrasco, em 1979. Evidencia-se, assim, a simultaneidade histórica entre a formação pós-graduada desses atores institucionais e a própria constituição da Abrasco.

As entrevistas revelam grande variabilidade de tempo de trabalho na saúde entre os dois grupos de entrevistados. Dois presidentes acusam o ingresso na primeira metade dos anos 1960; outros dois, na segunda metade dos anos 1970, e uma na década de 1980. Entre os coordenadores da comissão, duas ingressaram 
na saúde na segunda metade dos anos 1960, duas nos anos 1970, um exatamente em 1980, uma em 1987 e dois em meados dos anos de 1990.

Essas periodizações mostram que há uma geração de trabalhadores anterior à criação da Abrasco, principalmente da década de 1960, e outra posterior, dos anos 80 e 90. Mas há, sobretudo, muitos que se inserem exatamente nos anos da criação da Abrasco e da consolidação institucional do campo da Saúde Coletiva e do subcampo das CSHS.

\section{Trajetória nas Ciências Sociais e Humanas em Saúde}

Este segundo bloco de resultados refere-se diretamente à trajetória dos entrevistados na constituição e no desenvolvimento do subcampo das CSHS e permite identificar as especificidades das trajetórias, bem como aspectos que indicam padrōes semelhantes de inserção no subcampo e na Saúde Coletiva em geral.

A tônica dos depoimentos tendeu a ressaltar as oportunidades que o campo da Saúde Pública/Coletiva significou, à época, para os entrevistados e suas trajetórias profissionais. Também se identificaram, pelos relatos, as diferentes formas de inserção no campo, além de ter-se evidenciado o quanto o contexto social brasileiro condicionou não apenas a constituição da Saúde Coletiva e da Abrasco, como todo o subcampo das CSHS.

Tendo em vista o fato de que o objeto deste trabalho é a trajetória profissional dos entrevistados em relação à constituição das CSHS na Abrasco, alguns depoimentos foram excluídos deste tópico de análise, já que seus protagonistas estiveram vinculados à presidência da Associação, sem vinculação necessária ao subcampo em estudo. Apenas uma presidente apresenta trajetória intrinsecamente relacionada a esse subcampo. Sendo assim, o material que aqui se apresenta diz respeito, principalmente, aos relatos dos oito coordenadores da comissão e ao de uma presidente da Associação.

A análise identificou dois grupos de agentes no que se refere à inserção no campo: há os profissionais que ingressaram no período que nesta pesquisa se denomina a fase de constituição do campo da Saúde Coletiva e os que ingressaram posteriormente, quando o campo já se encontrava institucionalizado pela recente criação da Abrasco, período que chamaremos de fase de institucionalização.

O subcampo das CSHS se conecta a essa periodização, podendo-se atribuir a ele, também e de forma similar, as fases de constituição e institucionalização. 
É importante lembrar que tal periodização, estruturada a partir da análise do material, funciona neste trabalho mais como eixo traçador de algumas características principais do campo e de seu subcampo, e não propriamente como recorte histórico-social fixo, pois se reconhece que para além de datas e eventos pontuais, um campo científico-político se constitui e desenvolve inserido num processo histórico-social longo, não sendo fenômeno isolado. A periodização atende, assim, à ênfase analítica das principais características e dinâmicas presentes nesses diferentes momentos de desenvolvimento do campo e do subcampo do que, propriamente, à sua rígida datação.

As trajetórias dos profissionais que ingressaram no período que aqui se caracteriza como constituição estão relacionadas aos esforços de configuração e instituição do próprio campo da Medicina Social/Saúde Coletiva no Brasil e indicam estreita relação entre os percursos pessoais e os institucionais. Os cientistas sociais que ingressaram no campo da Saúde Coletiva na fase de sua constituição apresentam, em suas trajetórias, aspectos similares: foram, de uma maneira ou outra, convidados especialmente por médicos envolvidos nos projetos de reestruturação do ensino e assistência da Medicina Preventiva e da Atenção Primária à Saúde. Médicos esses generalistas ou preventivistas/“sanitaristas”, muitos deles sem essa formação específica, na medida em que não havia muitos cursos dessa natureza no país, a não ser o da Faculdade de Saúde Pública da Universidade de São Paulo (posteriormente, a Escola de Saúde de Minas Gerais e a Escola Nacional de Saúde Pública do Rio de Janeiro também passarão a formar sanitaristas). A inserção pelo convite fica evidente no depoimento de duas coordenadoras:

Me formei e comecei a trabalhar no setor saúde aqui da Unicamp, me formei em 1965 e em 1966 já estava na Unicamp na área da Saúde. Eu me formei aqui em Campinas, na PUC e já vim para o Departamento de Medicina Preventiva porque o departamento estava começando a se organizar. (entrevistada $n^{\circ}$ 06/ feminino/ Coordenadora de Comissão/ Serviço Social)

Vou te contar como é que eu entrei aqui [na UNIFESP]: Um dia um amigo falou assim 'Olha, tem umas coisas de Ciências Sociais lá na preventiva', e eu vim e me apresentei. O Dr. Nagibe, que era do departamento, me disse: "Se você demonstrar que é capaz de fazer alguma coisa, a gente pensa no assunto". Eu fiquei estonteada, porque eu mesma não sabia, e aí eu comecei a participar de umas aulas de Epidemiologia e comecei a quantificar os resultados dos trabalhos dos alunos. [...] Eu acho que tem que abrir um parêntese porque paralelamente a isso, o que é que estava acontecendo? O departamento vinha desde um encontro que teve em Viña del Mar, no qual foram 
fundados os departamentos de Medicina Preventiva, o de Ribeirão Preto e o nosso, e a gente tinha uma formação em Epidemiologia etc.. Mas já vinha da OPAS a ideia de que os cursos de Medicina deveriam incluir as Ciências Sociais. (entrevistada n ${ }^{\circ}$. 11/ feminino/ Coordenadora de Comissão/ Cientista Social)

Observa-se que a inserção dessas profissionais ocorreu diretamente em graduações do ensino médico, na perspectiva da institucionalização do ensino de matriz preventivista, com ênfase na relação saúde-comunidade.

As turmas de Medicina eram enormes, então para um trabalho de comunidade nós trabalhávamos junto com eles. No ensino de Ciências Sociais, particularmente no acompanhamento dos alunos nesse programa de saúde da comunidade, na discussão dos aspectos socioeconômicos e culturais que os estudantes se defrontavam nesses estudos das famílias que eles faziam. Então esse foi o primeiro contato, vamos dizer do ponto de vista profissional, que eu fui tendo também um contato com as Ciências Sociais. (entrevistada n ${ }^{\circ}$ 06/ feminino/ Coordenadora de Comissão/ Serviço Social)

[...] eles me colocaram para trabalhar no centro de saúde, porque assim eu não ocupava uma vaga, e ali eu fiquei durante um tempo e quando eles quiseram me contratar formalmente, eu disse que não, porque eu queria ser docente [...] (entrevistada $\mathrm{n}^{\mathrm{o}}{ }^{11}$ / feminino/ Coordenadora de Comissão/ Cientista Social)

Ainda no período de constituição do campo da Saúde Coletiva, há duas coordenadoras da comissão cujos ingressos no campo datam de 1974 e 1979, datas muito próximas à criação da Abrasco em 1979. Como se verá, sua entrada se deu através do ensino, porém no nível de pós-graduação, em programas strictu ou lato sensu.

Essa trajetória profissional teve início no IUPERJ, onde eu era pesquisadora assistente, e a minha entrada no campo da saúde acontece em um curso internacional de Política de Saúde, onde tinha um bloco específico de Estado e políticas de saúde [...] Em verdade, foi esse curso que me trouxe a disposição para fazer Ciências Sociais em Saúde. (entrevistada n ${ }^{\text {o. }}$ 13/ feminino/ Coordenadora de Comissão/ Sociologia)

Quando chega em 1974, o professor Hésio Cordeiro foi na PUC me convidar para fazer parte de um grupo que estava querendo criar um mestrado em Medicina Social, porque as Universidades não tematizavam a questão da saúde em relação à sociedade... Tinha que ser uma pós-graduação em Medicina Social... Nem as pós-graduações estavam bem estruturadas, elas estavam se estruturando... Ele disse que estavam querendo fazer um mestrado multidisciplinar, muito avançado! Ele disse que já tinham professores de Economia, de Ciências Políticas, de Filosofia, que era o Roberto Machado... E eles estavam precisando de uma socióloga. (entrevistada n ${ }^{\text {o. }}$ 09/ feminino/ Coordenadora de Comissão/ Sociologia)

Os depoimentos indicam que as Ciências Sociais, hoje reconhecidas como constitutivas do campo da Saúde Coletiva pelo arcabouço teórico aportado, não 
protagonizaram a liderança desse campo em sua fase inicial. Essa liderança esteve posicionada na figura de profissionais médicos, do ensino ou dos serviços, também lideranças primazes do movimento da Reforma Sanitária (ESCOREL, 1999).

Ao período de constituição segue-se um momento de fortalecimento interno ao próprio campo da Saúde Coletiva, que agregou e ampliou o âmbito da sua atuação. Esse é o período de institucionalização do campo e, por decorrência, das CSHS, que pode ser datado como aquele imediatamente posterior à criação da Abrasco, na década de 1980, estendendo-se ao início dos anos 1990. É no percurso dessas duas décadas que se consolidam as grandes áreas conformadoras da Abrasco, a Epidemiologia e as Ciências Sociais ${ }^{1}$.

Nessas duas décadas, também se identificam dois grupos, diferenciados por pequenas nuances: os que ingressaram no campo nos anos 1980 - três entrevistados; e os que ingressaram no campo nos anos 1990 - dois entrevistados. O primeiro grupo ingressou muito próximo à criação da Abrasco, num contexto de transição entre a constituição e a institucionalização, de certa forma vinculando e amalgamando a primeira geração e as futuras. O segundo grupo, que estreita seus laços com o campo na década de 1990, o faz em contexto já institucionalizado.

As características dessas aproximaçōes são diferentes e expressam não só os interesses pessoais como as também diferentes demandas institucionais da Saúde Coletiva e das CSHS. As inserções realizadas nos anos imediatos à criação da Abrasco assemelham-se às dos anos anteriores, pois se deram por meio do ensino, porém no nível da pós-graduação. As inserções ocorridas nos anos 1990 se relacionam muito mais à pesquisa, indicando a ampliação do escopo de atuação no campo.

Eu fiz mestrado em Antropologia Social e doutorado em Saúde Pública, mas sempre em Saúde Pública voltada para as questóes sociais. Durante esse período eu fui professora da Escola Nacional de Saúde Pública, de onde eu sou até hoje [...]. Eu entrei como professora, fui coordenadora da pós-graduação em Saúde Pública [...]. (entrevistada ${ }^{\circ}$. $04 /$ feminino/ Presidente/ Ciências Sociais)

Logo após a realização do mestrado (com uma temática bem diferente das questôes relacionadas à saúde) comecei a me interessar pela Sociologia/Antropologia da Saúde. Isso aconteceu na primeira metade de 1980. Meu interesse original era compreender as relaçôes existentes entre a Biomedicina e as chamadas, na época, medicinas tradicionais. (entrevistado n ${ }^{\text {o. }}$ 12/ masculino/ Coordenador de Comissão/ Filosofia)

[...] então eu vim [para a Fiocruz] primeiro para o projeto de memória; eu era muito jovem, isso era em 1987, e não tinha nenhuma pesquisa específica na área de saúde, nem a dissertação de mestrado eu tinha defendido ainda, que era sobre movimentos 
sociais urbanos [...]. A partir daí eu ingressei para esse projeto de memória da previdência. (Entrevistada no. 10/ feminino/Coordenadora de Comissão/ Ciências Sociais)

Os profissionais que ingressaram no campo na década de 1990, por sua vez, apresentam forte intencionalidade e interesse em atuar no subcampo, tendo, inclusive dirigido sua atuação nessa perspectiva. Esses serão os profissionais mais diretamente formados no interior do próprio campo da Saúde Coletiva e no subcampo das CSHS.

Eu me graduei em Medicina no Rio de Janeiro, em 1983. Mas desde a época que eu estava fazendo a graduação, eu sempre trabalhei com as coisas marginais dentro da Medicina [...]. E um pouco por conta disso, é que fui me aproximando e de vez; quando eu terminei a faculdade, o meu projeto era de entrar para o que era então mestrado em Medicina Social [...]. E aí, eu saí da faculdade, fiz residência, porque eu queria fazer o mestrado, aí eu terminei, fiz e entrei logo no mestrado e aí, a minha orientadora foi a Madel [Filósofa com atuação no subcampo de CSHS desde a fase de sua constituição]. (entrevistado $\mathrm{n}^{\mathrm{o} .}$ 07/ masculino/ Coordenador de Comissão/ Medicina)

[...] antes de terminar o doutorado eu tive a oportunidade de saber que estava se construindo o projeto do ISC. Eu estive no Brasil em 93, já tinha assim alguns indícios: 'olhe, tem um grupo da Faculdade de Medicina que está aí se mobilizando', mas concretamente antes de terminar o doutorado, eu regressei com a minha família no início de 95, final de 94/95, e fui conversar com Naomar, que depois se tornou diretor do ISC e reitor da UFBA. Coloquei que tinha conhecido, já conhecia ele, como psiquiatra e tal, mas tinha conhecido um trabalho dele vinculado ao meu tema de tese, e o convidei para ser co-orientador. [entrevistada $\mathrm{n}^{\circ}$. $08 /$ feminino/ Coordenadora de Comissão/ Psicologia]

Reconhecendo que um campo científico se constitui e desenvolve no contexto de um processo histórico-social, não sendo fenômeno isolado, os relatos fornecem um rico material. Por meio das trajetórias autobiográficas é possível acompanhar as conexôes do campo ao contexto político-social do país.

Durante a década de 1970, se eles viam que tinha algum marxista, ou qualquer coisa que eles inventavam na cabeça deles, botavam na rua... E realmente em 1975 eu e um grupo grande do departamento de Sociologia fomos para a rua... Mas eu já estava começando lá na Medicina Social, porque o mestrado mesmo, o ano letivo era em 1975. Eu comecei a trabalhar lá em junho de 1974, mas só em 1975 comecei a dar aulas [...]. Aí foi minha entrada na saúde, na Saúde Coletiva...” (entrevistada n ${ }^{\text {o. }} 09$ / feminino/ Coordenadora de Comissão / Ciências Sociais)

Naquela época de repressão política, eu tive que sair do país, e, voltando, eu fiz mestrado em Antropologia Social e doutorado em Saúde Pública, mas sempre em Saúde Pública voltada para as questôes sociais." (entrevistada n ${ }^{\circ .}$ 04/ feminino/ Presidente/ Ciências Sociais) 
Naquela época, os médicos sanitaristas estavam começando o movimento sanitário, em 1985, procurando uma maior institucionalização, e eu entrei nessa militância [...] (entrevistada n ${ }^{\circ}$. 13/ feminino/ Coordenadora de Comissão/ Ciências Sociais)

Então, na verdade, eu vim para trabalhar na área de saúde a partir desse projeto e desse movimento, de um lado, um movimento na área da saúde, e, de outro, um movimento de valorização da memória que marcou bem esses meados dos anos 1980 . (entrevistada ${ }^{\circ}$. 10/ feminino/ Coordenadora de Comissão/ Ciências Sociais)

$\mathrm{Na}$ trajetória desses agentes, quando se levam em conta as diferentes regiōes do país, verificam-se sutis diferenças. Enquanto os profissionais sediados no Rio de Janeiro e na Bahia ingressaram diretamente na formação pós-graduada e na pesquisa, os profissionais de São Paulo ingressaram nas graduações de Medicina.

A diversidade de interesses que conduziu esses profissionais para a saúde fica evidente nos relatos. Alguns se converteram para a saúde no decorrer da formação pós-graduada; outros foram estimulados pelo convite de profissionais/docentes do campo; houve, ainda, os movidos por interesses particulares, temáticos e teóricos. Essa diversidade indica diferentes experiências pessoais, diferentes escolhas na formação básica e diferentes alinhamentos às questões da saúde. Entretanto, para todos, subsiste a sensação sutil e perene de situar-se no meiofio de disciplinas e campos de saberes, na interface de instituições solidamente estabelecidas, entre multiplicidades interpretativas.

A criação de novas unidades em qualquer instituição sempre gera tensões, ciúmes... Então, a partir daí, a gente conseguiu, em função do trabalho do grupo inteiro, consolidar nosso espaço institucional. (entrevistada no 10 / feminino/ Coordenadora de Comissão/ Ciências Sociais)

Na verdade, a minha trajetória, a gente costuma usar uma expressão dentro do ISC para aquelas pessoas que atuam, claramente, em mais de um campo, um campo com uma relativa diversidade, a gente brinca que é anfíbio. Então, eu acho que desde sempre, eu fui meio anfíbio. (entrevistada n $\mathrm{n}^{\mathrm{o}}$ 08/ feminino/ Coordenadora de Comissão/ Psicologia)

No entanto, para além dessas sensações de desconforto disciplinar e desafios institucionais solidamente construídos, o campo da Saúde Coletiva, e nele o das CSHS, demonstra sua vitalidade, inovação e criatividade, sempre vinculadas às questôes sociais do país.

Aí eu vi que o Hésio e o grupo dele, e aí tinha o Reinaldo Guimarães, o José Carvalho de Noronha... Tinha umas pessoas que ainda nem tinham mestrado, de modo que instrumentalmente e até simbolicamente eles foram todos meus alunos, porque a primeira turma de mestrado, eles que fizeram, mas era uma coisa mais formal porque ali 
não havia uma pessoa que soubesse mais do que outra, era uma construção coletiva, era um projeto coletivo de construção de um mestrado nessa área de Saúde e Sociedade, de Saúde e Política, de pensar a saúde, essa coisa da filosofia... Que deu origem a essas visitas todas que houve no Instituto de Medicina Social: Michael Foucault e toda aquela turma que pertencia ao fervilhamento dos anos 1970 de transformações no campo da saúde... Então, eu fiz parte disso, eu entrei num momento histórico importante para a questão da saúde e para a configuração desse campo, que mais tarde, uma década depois, veio a se chamar de Saúde Coletiva... (entrevistada n ${ }^{0 .} 09$ / feminino/ Coordenadora de Comissão/ Ciências Sociais)

\section{Discussão}

A produção de um campo científico, evidentemente, não passa ao largo de seus praticantes, de seus agentes, segundo as formulações de Bourdieu (2004). O campo científico, para além do conteúdo textual da produção e do contexto social no qual está inserido, envolve o universo intermediário desses dois polos os agentes e as instituições. A trajetória dos profissionais da Saúde Coletiva diz muito sobre a institucionalização desse campo e, nele, o das CSHS. As relações objetivas entre agentes e as posiçôes que ocupam na estrutura institucional por eles herdada ou construída revela uma dimensão importante do campo, em que "agentes (indivíduos ou instituiçôes) caracterizados pelo volume de seu capital [científico] determinam a estrutura do campo [...]" (BOURDIEU, 2004, p. 24). Tais pressupostos reafirmam a pertinência de estudos desta natureza, na perspectiva de Bourdieu, uma vez que as trajetórias individuais estão amalgamadas à trajetória científica do campo.

A recuperação das trajetórias de presidentes e coordenadores permitiu identificar o perfil desse conjunto de agentes, sua formação científica, básica e pós-graduada e aspectos importantes do seu percurso nas CSHS. As diferenças também puderam ser percebidas quanto à formação e o percurso no campo e no subcampo.

Chamam a atenção os anos 1960 e o início dos anos 1970, que classificamos neste estudo de período de constituição, pois se referem ao momento em que se articulou na América Latina um debate teórico-político sobre a saúde, com o apoio da Organização Pan-Americana de Saúde (OPAS). Além disso, no Brasil, enfrentavam-se os anos de chumbo da ditadura militar por meio da resistência democrática, que marca indelevelmente o campo da Saúde Coletiva e que, de 
acordo com diferentes autores (PAIM, 2007; CANESQUI, 2008; LOYOLA, 2012; NUNES, 2009), congrega proposiçōes genuinamente brasileiras.

No conjunto, o perfil dos profissionais que constituem o subcampo das CSHS é diversificado e híbrido, indicando a grande interdisciplinaridade intrínseca à Saúde Coletiva como um todo e desse subcampo em particular - todos, porém, conectados ao objeto saúde. Tal diversidade é menor no que se refere à localização geográfica das instituições formadoras, que apresentam clara concentração no Sudeste.

O período aqui denominado de institucionalizaçáo é caracterizado, principalmente, pela intencionalidade desses agentes em atuar no campo como um todo e, muito especificamente, nesse subcampo. A institucionalização das CSHS se dá em paralelo à do próprio Sistema Único de Saúde (SUS), que em 1988 se torna legal e legítimo na Constituição Federal e em 1990 ganha força de lei, com a Lei Orgânica da Saúde (Lei 8.080/1990), confirmando e legitimando sua implantação (CANESQUI, 2008). Esse fenômeno vai estimular, a posteriori, a desvinculação da política do subcampo das Ciências Sociais, quando então se conforma a comissão de política, planejamento e gestão da Abrasco no ano de 2001. Esse contexto político passa a demarcar os debates acerca da implementação do SUS, e as Ciências Sociais e Humanas não permanecerão de fora, desenvolvendo principalmente estudos sobre os usuários (culturas, gêneros, etnias, representaçōes saúde-doença) e práticas em saúde (críticas ao modelo biomédico, por exemplo).

A grande diversidade nas trajetórias intelectuais dos entrevistados revelou-se na adesão ao campo da Saúde Coletiva, por meio de temas clássicos das Ciências Sociais, migrando posteriormente para as questôes de saúde, ou por já estarem inseridos em algum serviço de saúde ou programa de ensino, estimulando-se a permanecer no campo.

\section{Considerações finais}

Este artigo divulga os resultados de pesquisa sobre a trajetória de profissionais na constituição das Ciências Sociais em Saúde na Abrasco. O curto período de existência desse subcampo no Brasil e suas especificidades intrínsecas (IANNI, 2011b ; LOYOLA, 2012; MINAYO, 2013) fazem com que essa 
genealogia empírica se conecte às perspectivas da sua contribuição teórica e configuração histórica: passada, presente e futura. Também se posiciona como uma contribuição à configuração histórica do campo da Saúde Coletiva no seu conjunto. Tal importância se reafirma justamente pelo fato do campo e seu subcampo terem uma história muito recente. Seus agentes - que os constituíram e institucionalizaram - continuam, muitos deles, atuando ativamente na conformação de novos rumos e novas proposições.

Acredita-se que a compreensão desse processo é extremamente profícua aos debates atuais que se realizam sobre o lugar das Ciências Sociais e Humanas no campo da Saúde Coletiva e no contexto da produção científica brasileira; reiterando, evidentemente, o papel central que essas ciências assumem na contemporaneidade, fornecendo arcabouço teórico e metodológico para a compreensão social, suas dinâmicas, processos e relações constitutivas. ${ }^{2}$

\section{Referências}

BARDIN, L. Análise de Conteúdo. Lisboa: Edições 70, 1979. 280p.

BROOM, A.; WILLIS, E. Competing paradigms and health research. In: SAKS, M.; ALLSOP, J. (Eds.) Researching health: qualitative, quantitative and mixed methods. London: Sage, 2007.

BARROS, N.F.; SPADACIO, C. A formação do pós-graduando no mundo contemporâneo da pesquisa. Saúde e Sociedade. São Paulo, v. 20, n. 1, jan./mar. 2011.

BOURDIEU, P. Os usos sociais da ciência. Por uma sociologia crítica do campo científico. São Paulo: Unesp, 2004. 86p.

CANESQUI, A.M. Introdução: os novos rumos das Ciências Sociais e Saúde. In:

(Org.) Ciências Sociais e Saúde. São Paulo: Hucitec, 1995. p. 19-35.

As Ciências Sociais e Humanas em Saúde na Associação Brasileira de Pósgraduação em Saúde Coletiva. Physis. Revista de Saúde Coletiva. Rio de Janeiro, v. 18, n. 2, p. 215-250, 2008.

ESCOREL, S. Reviravolta na Saúde. Origem e articulação do movimento sanitário. Rio de Janeiro: Fiocruz, 1999.

GABE, J.; CALNAN, M. (Orgs.). The new sociology of the health service. New York: Routledge, 2009.

IANNI, A.M.Z. Questôes contemporâneas sobre natureza e cultura: notas sobre a Saúde Coletiva e a Sociologia no Brasil. Saúde e Sociedade. Rio de Janeiro, v. 20, n. 1, p. 32-40, 2011 a. 
A Saúde Coletiva como campo científico e político na América Latina. In:

FERREIRA, L.C. (Org.). A questão ambiental na América Latina. Teoria social e Interdisciplinaridade. Campinas: Unicamp, 2011b. p. 141-157.

IANNI, A.M.Z. et al. Questôes contemporâneas nas Ciências Sociais em Saúde: o estudo de temas emergentes nos congressos brasileiros de Ciências Sociais e Humanas em Saúde, Abrasco 1995-2007. 2012. 226p. (Relatório final de pesquisa). Edital MCT/CNPq 14/2009 - Universal.

LOYOLA, M.A. O lugar das Ciências Sociais na Saúde Coletiva. Saúde e Sociedade. Rio de Janeiro, v. 21, n.1, p. 9-14, 2012.

MINAYO, M.C.S. A produção de conhecimentos na interface entre as ciências sociais e humanas e na saúde coletiva. Saúde e Sociedade. Rio de Janeiro, v. 22, n. 1, p. 21-31, mar. 2013. NASCIMENTO, J.L. Uma (con)figuração: cientistas sociais, antropólogos, sociólogos e cientistas políticos em saúde no Brasil. 2011. 285p. Tese (Doutorado em Saúde Coletiva) - Departamento de Medicina Preventiva e Social da FCM/Unicamp. São Paulo, Campinas, 2011.

NUNES, E.D. A Metodologia qualitativa em saúde. Dilemas e desafios. In: BARROS, N.F.; CECATTI, J.G.; TURATO, E.R. (Orgs.). Pesquisa qualitativa em saúde: múltiplos olhares. São Paulo: Hucitec, 2005. p. 15-24.

- Saúde Coletiva: uma história recente de um passado remoto. In: CAMPOS, G.W.S. et al. (Orgs.). Tratado de Saúde Coletiva. São Paulo: Hucitec, 2009. p. 19-51.

. Sobre a sociologia da saúde. São Paulo: Hucitec, 1999.

Tendências e perspectivas das pesquisas em Ciências Sociais na América Latina: uma visão geral. In: (Org.) As Ciências Sociais em Saúde na América Latina: tendências e perspectivas. Brasília: OPAS, 1985. p. 29-79.

PAIM, J.S.; ALMEIDA FILHO, N .de. Saúde coletiva: uma "nova saúde pública” ou campo aberto a novos paradigmas? Rev. Saúde Pública. São Paulo, v. 32, n. 4, ago. 1998.

Reforma Sanitária Brasileira: contribuição para a compreensão e crítica. Tese (Doutorado em Saúde Coletiva) - Universidade Federal da Bahia, Salvador, 2007.

Uma análise sobre o processo da Reforma Sanitária brasileira. Saúde em Debate. Rio de Janeiro, v. 33, n. 81, p. 27-37, jan./abr. 2009.

SARTI, C.A. Saúde e sofrimento. In: MARTINS, C.B.; DUARTE, L.F.D. (Coord). Horizonte das Ciências Sociais no Brasil. Antropologia. São Paulo: ANPOCS, 2010. p. 197-223.

TEIXEIRA, S.M.F. As Ciências Sociais em Saúde no Brasil. In: NUNES, E.D. (Orgs.) As Ciências Sociais em Saúde na América Latina. Tendências e perspectivas. Brasília: OPAS, 1985. p. 87-109. 


\section{Notas}

${ }^{1}$ Somente em 2010, a Política será desagregada das Ciências Sociais, organizando seu primeiro encontro, o I Congresso Brasileiro de Política, Planejamento e Gestão em Saúde. Recentemente, a Comissão de Ciência \& Tecnologia em Saúde passa a integrar as áreas da Saúde Coletiva.

2 Esta pesquisa foi financiada pelo CNPq em Edital MCT/CNPq 14/2009 - Universal, correspondendo ao Processo CNPq No. 470389/2009-5. A.M.Z. Ianni realizou coleta e análise de dados, discussão dos resultados, revisão teórica e redação final do artigo. C. Spadacio realizou revisão teórica e redação final do artigo. R. Barboza, O.S.F. Alves, S.D.L. Viana e A.T. Rocha realizaram a coleta e a análise de dados. 


\section{Abstract}

\section{Professional trajectory in the formation of}

Social Sciences in Health in Abrasco

Nowadays, the importance of social sciences to the consolidation of Public Health in Brazil is increasingly felt. Therefore, understanding the professional history that somehow founded the field and kept it is ultimately understanding the very theoretical path and practice in this area, as evidenced also in congresses of Social Sciences in Health conducted by Abrasco. In the context of this discussion, this article presents a profile of the mapping of the presidents of Abrasco and coordinators of Social Sciences Committees who occupied these positions between 1995 and 2011, when Brazilian Congress of Social Sciences and Humanities in Health were held. We conducted 13 interviews with presidents Abrasco and coordinators of the Social Sciences Committee, in its different administrations. Although this article is more descriptive, conccerning the establishment and institutionalization of Social Sciences in Health in Abrasco, it is believed that understanding the forming process of this subfield from the speech of its agents is extremely helpful for the current debates on the role played by Social Sciences in Public Health.

> Palavras-chave: collective health; social sciences in health; professional trajectory. 